\title{
DIAGNÓSTICO DE LA TOXOCAROSIS HUMANA
}

\author{
William H. Roldán ${ }^{1, a}$, Yrma A. Espinoza ${ }^{1,3, c}$, Pedro E. Huapaya ${ }^{2, b}$, Susana Jiménez ${ }^{1, d}$
}

\begin{abstract}
RESUMEN
La toxocarosis humana es una importante zoonosis parasitaria causada por formas larvarias de especies del género Toxocara, un parásito nematodo de los perros y los gatos. La migración de la larva por los diferentes tejidos blandos en el ser humano genera una serie de entidades clínicas en el paciente, tales como el síndrome de larva migrans visceral, la toxocarosis ocular y la neurotoxocarosis. El diagnóstico definitivo es mediante la histopatología en biopsias, pero resulta ser casi imposible de realizar y actualmente su diagnóstico se establece mediante el análisis de la sintomatología clínica, los antecedentes epidemiológicos del paciente y el uso de pruebas hematológicas e inmunológicas de laboratorio que son las que finalmente ayudan a confirmar la sospecha clínica de la enfermedad. El propósito del presente artículo es actualizar los conocimientos que se tienen sobre el uso de las diferentes herramientas para establecer el diagnóstico y el monitoreo de la toxocarosis humana.
\end{abstract}

Palabras clave: Toxocara; Zoonosis; Diagnóstico; Pruebas inmunológicas; Revisión (fuente: DeCS BIREME).

\section{DIAGNOSIS OF HUMAN TOXOCAROSIS}

\begin{abstract}
Human toxocarosis is an important parasitic zoonosis caused by larval stages of Toxocara species, the roundworms from dogs and cats. Larval migration through different soft tissues in the human generates several clinical entities in the patient, such as visceral larva migrans, ocular toxocarosis, and neurotoxocarosis. Definitive diagnosis by histopathological methods is very difficult or almost impossible and, nowadays, the diagnosis is usually made by clinical signs/symptoms, epidemiological background of the patient and the use of hematological and immunological tests which finally help to confirm the clinical suspicion of the illness. The purpose of this paper was to update the available knowledge on the use of different tools for both the diagnosis and following up of human toxocarosis.
\end{abstract}

Key words: Toxocara; Zoonoses; Diagnosis; Immunologic test; Review (source: MeSH NLM).

\section{INTRODUCCIÓN}

La toxocarosis humana es una importante zoonosis parasitaria causada por las formas larvarias de especies de nematodos del género Toxocara, cuyos hospederos definitivos son el perro y el gato (Toxocara canis y T. cati, respectivamente). De forma accidental, el ser humano ingiere los huevos larvados de estos parásitos, los que eclosionan en el tracto intestinal y las larvas liberadas atraviesan el epitelio intestinal y los vasos sanguíneos, donde pueden migrar hacia los diferentes órganos viscerales y tejidos del cuerpo humano ${ }^{(1)}$.

Un fenómeno interesante es que estos parásitos no pueden evolucionar hacia formas adultas en el ser humano y quedan restringidos a su forma larval, pudiendo migrar durante meses e inclusive años, ocasionando reacciones inflamatorias locales o sistémicas según el órgano afectado ${ }^{(1,2)}$. En ocasiones, el sistema inmune puede incluso matar al parásito; sin embargo, la inmunidad generada en una primera infección no logra proteger contra futuras reinfecciones ${ }^{(3)}$. Se ha descrito que las larvas pueden sobrevivir durante muchos años e incluso de por vida en el hospedero humano, causando hemorragia, necrosis, reacción inflamatoria eosinofílica y formación de granulomas ${ }^{(1-4)}$.

\section{PRESENTACIÓN CLÍNICA DE LA TOXOCAROSIS HUMANA}

El espectro de manifestaciones clínicas en la toxocarosis varía ampliamente desde casos asintomáticos a infecciones generalizadas ${ }^{(5)}$. Las manifestaciones clínicas y el curso de la enfermedad se encontrarán determinados por la cantidad del inóculo, la frecuencia de reinfecciones en el individuo, la localización de la larva migrante en el órgano afectado y la respuesta del hospedero.

\footnotetext{
Departamento Académico de Microbiología Médica, Facultad de Medicina, Universidad Nacional Mayor de San Marcos, Lima, Perú.

Dirección Regional de Salud, Ministerio de Salud, Lima, Perú

Sección Científica de Parasitología, Instituto de Medicina Tropical “Daniel A. Carrión”, Universidad Nacional Mayor de San Marcos, Lima, Perú.

a Tecnólogo médico; b Médico cirujano; ${ }^{\mathrm{c}}$ Biólogo; d Técnico en laboratorio.
}

Recibido: 03-11-10 Aprobado: 01-12-10 
La medida del inóculo y la frecuencia de las reinfecciones no pueden ser medidas en el ser humano pero estas pueden ser asumidas debido a la frecuencia de ambientes contaminados con huevos de Toxocara spp. o por la proporción de niños con características de geofagia en la localidad o región estudiada ${ }^{(2,5,6)}$.

Las larvas migrantes pueden ser identificadas mediante el examen clínico y el uso de pruebas de diagnóstico por imagen para observar los granulomas, ya sea en el ojo, el cerebro o el hígado ${ }^{(1,2,5)}$. Aun cuando no se pueda observar directamente las larvas migrantes, el diagnóstico por imagen resulta ser de mucha ayuda para sospechar del agente etiológico, sin embargo, toda sospecha tiene que ser confirmada por algunas pruebas adicionales de laboratorio, como se verá mas adelante.

Una gran proporción de infecciones por Toxocara resulta ser asintomática o cursa con síntomas inespecíficos (7). Los órganos involucrados con mayor frecuencia son el hígado, los pulmones, el cerebro, los ojos, el corazón y los músculos esqueléticos ${ }^{(1-5)}$. Clínicamente, la forma crónica se manifiesta en forma generalizada (el síndrome de larva migrans visceral) o en forma localizada (toxocarosis ocular), siendo esta última la más frecuente y la que puede originar ceguera en el $64 \%$ de los casos ${ }^{(1,2,5)}$

Las manifestaciones de la infección humana por larvas de Toxocara podrían dividirse en una etapa aguda (que suele ser incierta e inespecífica), una fase latente y una fase crónica. La fase aguda de la infección ocurre inmediatamente después de haberse producido la ingesta accidental de huevos infectantes del parásito, dichos huevos sufren la acción digestiva de los jugos gástricos en el estómago y de las enzimas pancreáticas en el intestino delgado, donde las larvas logran liberarse. Estas larvas atraviesan el epitelio intestinal y migran hasta alcanzar los vasos sanguíneos y por medio de ellos logran llegar al hígado, que es el primer órgano en ser afectado. La respuesta inflamatoria exagerada del hígado (hepatomegalia) va a depender de la cantidad de larvas migrantes que logran ser ingeridas por el hospedero, ya que un minúsculo número de larvas puede lograr pasar desapercibido hacia la vena porta sin producir signos y desde allí, pueden viajar hacia otros órganos como el corazón, los pulmones, riñones y tejidos vascularizados; esta migración también puede incluir a órganos considerados inmunológicamente privilegiados como el globo ocular y el cerebro ${ }^{(1,2,5,7)}$. La migración larval puede manifestarse con síntomas inespecíficos como mialgias, fiebre, malestar general y puede ocasionar episodios de broncoespasmo o hiperreactividad bronquial, sobre todo en niños o personas predispuestas a esta situación (7-10). En esta etapa el diagnóstico es extremadamente raro ya que es muy difícil que exista la sospecha de la infección. Como hallazgo de laboratorio se puede encontrar eosinofilia, con lo que podría ser catalogado como un asma bronquial ${ }^{(3,9,11)}$.

Luego de la infección inicial, el parásito puede ser reprimido por la inmunidad y verse confinado a un tejido en particular y dependiendo de la capacidad de evasión de la respuesta inmune del parásito, este puede sobrevivir y mantenerse en forma latente sin causar signos o síntomas relevantes para poder sospechar de su presencia en el organismo ${ }^{(2,3)}$. Sin embargo, cuando existe un marcado proceso inflamatorio en los tejidos afectados, su sola presencia será causante de las manifestaciones futuras de la etapa crónica. La mayoría de las personas infectadas pueden reprimir de manera eficiente al parásito y destruirlo gracias a la activación de la repuesta inmunológica, de tal manera que solo quedarán, por un tiempo, anticuerpos contra el parásito como recuerdo de la infección que en algún momento sucedió ${ }^{(1,2)}$

La fase crónica ocurre como consecuencia del proceso inflamatorio ocasionado por la presencia del parásito en los tejidos, las manifestaciones clínicas dependerán del número de parásitos y de su localización en los tejidos u órganos del hospedero. De manera clásica existen dos síndromes que han sido bien documentados en la literatura mundial desde el primer reporte en los años 50: el síndrome de larva migrans visceral (LMV) y el síndrome de larva migrans ocular (LMO, actualmente llamado toxocarosis ocular). Sin embargo, el espectro de la patogénesis de la toxocarosis humana ha dado lugar a la descripción de otras formas, aunque menos conocidas, pero que han cobrado importancia clínica en los últimos años ${ }^{(1-5)}$.

El clásico síndrome de LMV es una forma grave y sistémica de toxocarosis que se caracteriza por alta eosinofilia, hepatoesplenomegalia, fiebre, afectación pulmonar, hipergammaglobulinemia y elevación de las isohemaglutininas anti-A y anti-B ${ }^{(4,12)}$. Los casos de LMV, suelen ser poco frecuentes y se producen casi exclusivamente en niños pequeños. Entre las posibles consecuencias de una prolongada eosinofilia están la fibrosis pulmonar ${ }^{(13)}$ y la miocarditis eosinofílica (14-16). Resulta ser más frecuente encontrar un síndrome de LMV incompleto que se limita a casos clínicos mucho menos graves en la que solo algunos signos de la clásica forma de LMV puede ocurrir, como por ejemplo, una hepatomegalia y una alta eosinofilia ${ }^{(5)}$. La clínica dependerá del órgano afectado, aunque muchas veces puede pasar desapercibida o ser asociada con otras etiologías ${ }^{(1,2)}$. Sin embargo, la característica más común es la eosinofilia crónica que muchas veces es el 
motivo que hace sospechar el diagnóstico ${ }^{(5)}$. Se puede encontrar hepatomegalia, fiebre y dolor abdominal cuando el compromiso es exclusivamente hepático ${ }^{(2,4)}$. Si el compromiso es pulmonar habrá disnea, tos seca, sibilancias, broncoespasmo, neumonitis intersticial e incluso puede producirse efusión pleural ${ }^{(17,18)}$. También puede presentarse con prurito y urticaria eosinofílica ${ }^{(19)}$. Otras manifestaciones incluyen artralgias, vasculitis, miocarditis, efusión pericárdica, etc.

La toxocarosis ocular es la forma localizada de la toxocarosis más conocida en la literatura mundial $(20,21)$. Esta entidad se produce como resultado de la invasión ocular de larvas de Toxocara, causando una serie de cuadros clínicos, entre ellas la endoftalmitis $(1-3,5,6,20,21)$, que puede ser confundida con un tumor maligno conocido como retinoblastoma ${ }^{(1-3)}$. El parásito está localizado dentro del globo ocular y ocasiona con frecuencia uveítis y retinitis por granulomatosis retiniana (22), que se confunde con otras etiologías y que puede pasar casi desapercibida, puesto que el paciente solamente aqueja disminución progresiva de la agudeza visual ${ }^{(1,3)}$; algunos casos presentan dolor o hemorragias intraoculares debido al intenso proceso inflamatorio ${ }^{(1,2)}$. La fibrosis consecuente empobrece el pronóstico de una visión en el futuro, el diagnóstico se sospecha con frecuencia luego de varios tratamientos alternativos sin resultado favorable, además, por las características de la enfermedad, es el oftalmólogo quien sospecha la infección, generalmente luego de que el paciente ha sido evaluado por otros médicos previamente ${ }^{(1,2,23,24)}$.

Otra forma localizada de la toxocarosis humana que ha cobrado importancia en los últimos años, gracias los reportes mundiales es el la neurotoxocarosis (NT) ${ }^{(25)}$, entidad clínica que resulta de la invasión del cerebro por larvas de Toxocara. En el cerebro, las larvas de Toxocara no están encapsuladas y las huellas de su migración por lo general comprenden pequeñas áreas de necrosis y una mínima infiltración inflamatoria ${ }^{(26)}$. Por lo tanto, en la NT varios casos son asintomáticos, mientras que en los otros casos la sintomatología puede variar ampliamente. Un estudio de casos y controles en seres humanos infectados por Toxocara llegó a la conclusión de que la migración de las larvas en el cerebro humano no necesariamente induce síntomas o signos neurológicos (27); sin embargo, algunos síntomas tales como déficit neurológico, convulsiones focales o generalizadas, trastornos del comportamiento y meningoencefalitis eosinofílica se han reportado en los distintos casos humanos de toxocarosis ${ }^{(28,29)}$. El conocimiento que se tiene gracias a las infecciones experimentales en ratones, indica que la proporción de larvas de Toxocara localizadas en el cerebro puede aumentar en el transcurso de la infección ${ }^{(30,31)}$ con una pobre respuesta inmunológica local ${ }^{(32)}$. Otras manifestaciones del sistema nervioso central son demencia, meningoencefalitis, mielitis, la vasculitis cerebral, epilepsia y neuritis óptica. Aunque raros, también se ha descrito manifestaciones que comprenden al sistema nervioso periférico como radiculitis, afección de nervios craneales o compromiso músculo esquelético ${ }^{(25,33)}$.

Otra forma de la toxocarosis poco conocida en la literatura pero que tal vez resulte ser la más frecuente es la toxocarosis encubierta ${ }^{(34)}$. Este tipo de toxocarosis se caracteriza por tener signos y síntomas inespecíficos y que no entran en la categoría de los clásicos de VLM, LMO o NT. La toxocarosis encubierta parece depender menos de una reacción local a las larvas de Toxocara, se puede considerar más como una respuesta inmunopatológica de algún órgano afectado. La expresión clínica es muy variable y puede presentarse como una afección pulmonar como asma, bronquitis aguda o neumonitis con o sin síndrome de Loeffler ${ }^{(35-37)}$; trastornos dermatológicos como una urticaria crónica o eczema ${ }^{(38)}$, linfadenopatía, miositis y artralgia ${ }^{(5,39,40)}$.

La asociación de la sintomatología clínica observada a una infección por Toxocara requiere de buenos conocimientos clínicos y evaluación de pruebas de laboratorio tales como la detección de anticuerpos lgG e IgE específica, eosinofilia e hipergammaglobulinemia $(1,2,5)$. La toxocarosis encubierta es a menudo confirmada por el alivio o desaparición de los síntomas inespecíficos luego de proceder con un tratamiento antihelmíntico $(2,5,6)$.

La toxocarosis asintomática o simplemente infección por Toxocara es a menudo diagnosticada por inmunoserología positiva y no requiere tratamiento antihelmíntico ${ }^{(6,41)}$. En algunos casos puede presentar una leve eosinofilia que no constituye peligro alguno para el paciente, sin embargo, es importante tener en cuenta esta condición, sobre todo para los estudios epidemiológicos de esta zoonosis que cada vez resulta ser más frecuente en nuestro medio ${ }^{(41)}$.

\section{DIAGNÓSTICO DE LA TOXOCAROSIS}

El diagnóstico definitivo de la toxocarosis en seres humanos se logra con la localización de las larvas migrantes en biopsias de los tejidos afectados del paciente (un hecho casi excepcional) o en necropsias ${ }^{(1-6)}$. Debido a que el parásito queda restringido a su forma larvaria, no es posible utilizar métodos coproparasitológicos para detectar huevos en las heces ${ }^{(1,2)}$. Por lo tanto, el uso de pruebas indirectas constituye la única herramienta disponible hasta el momento para poder confirmar la sospecha clínica en el paciente (Tabla 1) ${ }^{(1-3)}$. 
Tabla 1. Relación de pruebas auxiliares para el diagnóstico y el monitoreo de la evolución del tratamiento de la toxocarosis humana.

\begin{tabular}{|c|c|c|c|c|c|}
\hline Prueba auxiliar & Utilidad & Sensibilidad & Especificidad & Disponibilidad & $\begin{array}{c}\text { Monitoreo del } \\
\text { tratamiento }\end{array}$ \\
\hline Diagnóstico por imagen a & +++ & +++ & - & Disponible & +++ \\
\hline Fondoscopía ${ }^{\text {b }}$ & +++ & +++ & + & Disponible & +++ \\
\hline Eosinofilia & +++ & ++ & - & Disponible & +++ \\
\hline Dosaje total de lgE & +++ & ++ & - & Disponible & +++ \\
\hline ELISA-IgM & + & ++ & ND & Disponible & - \\
\hline ELISA-IgG ${ }^{c}$ & +++ & +++ & +++ & Disponible & - \\
\hline ELISA-IgG Avidez & +++ & +++ & ND & Restringido $^{e}$ & - \\
\hline ELISA-IgE & ++ & ++ & ++ & Restringido $^{e}$ & +++ \\
\hline Inmunoblot-lgG ${ }^{d}$ & +++ & +++ & +++ & Restringido $^{e}$ & - \\
\hline
\end{tabular}

(a) Ecografía, resonancia magnética y tomografía computarizada; (b) solo para casos oculares; (c) poco sensible en casos oculares; (d) prueba confirmatoria; (e) restringido a laboratorios de investigación.

$+++=$ Muy alto o muy importante;

$++=$ Alto o importante;

$+=$ Poco o aceptable;

- = No útil o no importante;

$\mathrm{ND}=$ No determinado

Actualmente, se debe tener en cuenta hasta cinco datos clínicos para catalogar una toxocarosis sintomática: las características de la historia del paciente, los signos y síntomas clínicos encontrados, una inmunoserología positiva, la presencia de eosinofilia y niveles incrementados de $\lg E$ total ${ }^{(5,6)}$.

La edad del paciente puede indicar un mayor riesgo de tener toxocarosis clínicamente sintomática. Por ejemplo, el clásico LMV o LMV incompleto suele ser más frecuente en niños menores de cinco años ${ }^{(5)}$. Por otro lado, la presentación clínica de la toxocarosis ocular puede variar según la edad; los casos de endoftalmitis difusa se encuentran con mayor frecuencia en niños entre 2 y 10 años, mientras que un granuloma en la retina puede encontrarse en niños mayores entre 6 y 14 años y pars planitis (inflamación ocular que afecta el área estrecha entre la iris y la coroides) entre los 6 y 40 años de edad ${ }^{(2,5)}$.

El sexo del paciente parece no ser un factor importante de predisposición a la toxocarosis en las poblaciones humanas, aunque algunos reportes puedan indicar lo contrario ${ }^{(42,43)}$, un factor de riesgo que clásicamente se encuentra vinculado con la toxocarosis es la geofagia, una conducta frecuente en niños menores de cinco años de edad $(1,2,42,43)$. Otro factor de riesgo conocido es el contacto con perros infectados (especialmente cachorros) que habitan en las zonas rurales, aunque actualmente esto parece no ser tan importante ya que recientes reportes epidemiológicos acerca de la toxocarosis indican que la infección humana se produce más por contaminación del medio urbano con huevos infectantes del parásito ${ }^{(1,5,44)}$.
El hallazgo de una eosinofilia periférica no debe ser catalogado como una característica patognomónica de la toxocarosis sintomática, ya que esta condición parece estar asociada con el número de larvas migrantes en el organismo y con la edad del paciente ${ }^{(1,3,5)}$. La eosinofilia suele estar presente más a menudo en niños que en adultos; además los granulomas tienden a ser de naturaleza eosinofílica cuando el número de larvas que están migrando es elevado, y esto generalmente esta asociado con una infestación en los dos principales órganos más afectados de la toxocarosis sintomática: el hígado y los pulmones ${ }^{(2,3,5)}$; es por eso que lo casos de LMV clásica o incompleta que se han reportado en la literatura mundial generalmente se han descrito asociados con la presencia de granulomas eosinofílicos. En los casos donde hay compromiso pulmonar exclusivo, los eosinófilos parecen estar asociados con granulomas que se generan en el tejido pulmonar y a la vez a la generación de síndromes asmatiformes (1-5). Un hecho interesante es que algunos autores han reportado que las larvas de Toxocara secretan antígenos con propiedades alergénicas ${ }^{(45-47)}$, un hecho que explicaría y apoyaría la hipótesis de que este parásito suele generar niveles elevados de IgE total, como se comentará más adelante.

Los estudios mediante el diagnóstico por imágenes tienen escaso valor y se usan dentro de la evaluación de las complicaciones o manifestaciones. El diagnóstico diferencial incluye otras entidades causantes de eosinofilia como reacciones a drogas, otras helmintiasis como ascarosis, estrogiloidiosis y fasciolosis, mientras que para la toxocarosis ocular son pocas las entidades, puesto que la lesión es característica y un oftalmólogo 
entrenado pude fácilmente realizar la sospecha clínica de la entidad ${ }^{(5,6)}$

De todos los datos anteriormente expuestos, la inmunoserología positiva constituye el marcador más importante de infección por Toxocara y abarca todos los espectros clínicos de la toxocarosis que hasta el momento se conocen. Sin embargo, la inmunoserología positiva no indica necesariamente una relación causal entre una infección por Toxocara y el caso clínico reciente de un paciente ${ }^{(1-6)}$.

Actualmente, el estudio inmunoserológico de la toxocarosis se realiza mediante el uso de pruebas inmunoenzimáticas, tales como el test de ELISA indirecto que utiliza antígenos de excreción/secreción de las larvas de Toxocara canis (TES) ${ }^{(48,49)}$ para detectar anticuerpos circulantes en el suero del paciente, aunque también se puede detectar en otros fluidos corporales del paciente, tales como en el humor vítreo y el líquido cefalorraquídeo ${ }^{(50-54)}$. Esta estrategia es de suma importancia puesto que, el poder detectar anticuerpos anti-Toxocara como un resultado de la producción local de las células del sistema inmune que ha invadido estas áreas del organismo, podría incrementar la sensibilidad de la prueba al mismo tiempo que permitiría confirmar el diagnóstico de la enfermedad. Sin embargo, hasta el momento no se ha estandarizado la prueba de ELISA para el uso de estos líquidos corporales en el diagnóstico de formas localizadas de la toxocarosis sintomática ${ }^{(6)}$.

La prueba de ELISA ha sido desarrollada y estandarizada principalmente para la detección de anticuerpos lgG anti-Toxocara con una sensibilidad que varía entre 80 y $100 \%$ y una especificidad de 90 a $95 \%(1,2,6,55)$. Estos valores pueden variar según la región geografica donde se realice la prueba, ya que en países tropicales donde existen zonas endémicas de otras helmintiasis y poliparasitismo, las reacciones cruzadas suelen ser frecuentes $y$, por lo tanto, se obtienen falsos positivos en los resultados ${ }^{(2,6)}$. Esto no sucede en los países europeos donde los casos de helmintiasis son esporádicos ${ }^{(6)}$. Cuando esto ocurre, se suele recurrir a algunas estrategias para incrementar la especificidad de la prueba; uno de ellos constituye la absorción previa de los anticuerpos inespecíficos con extractos antigénicos de Ascaris spp. de tal manera que solo los anticuerpos específicos puedan ser detectados durante el ensayo inmunoenzimático ${ }^{(55-57,58)}$.

Un resultado falso positivo puede darse en pacientes con ascariosis, estrongiloidosis, triquinelosis, fasciolosis y otras helmintiosis relacionadas (56). Un aspecto por considerar es cuando el paciente se encuentre coinfectado con otros helmintos, problema que puede ser resuelto indicando al paciente un análisis coproparasitológico seriado ${ }^{(57,58)}$

Los casos de falsos negativos son raros y, generalmente, pueden ocurrir en infecciones localizadas leves (como en el caso de un LMO) o en individuos con una infección muy antigua ${ }^{(1,2)}$. Se debe tomar en cuenta que la inmunosupresión de cualquier índole puede afectar la respuesta inmunológica del paciente y la baja producción de anticuerpos contra el parásito.

Debido a la existencia de reacciones cruzadas, varios autores recomiendan confirmar el resultado del ELISA haciendo uso de la prueba del western blot o simplemente llamado inmunoblot (WB). Esto se debe a que los componentes de alto peso molecular (PM) de los antígenos TES contienen epítopes antigénicos de reacción cruzada con otros helmintos. Este problema se puede resolver con el uso de la prueba de WB que de alguna manera fracciona o divide los componentes de los antígenos TES de acuerdo con su PM, y fácilmente pueden identificarse que los componentes de bajo PM resultan ser más específicos para confirmar el serodiagnóstico de la toxocarosis ${ }^{(5,6)}$. Existen diversos métodos para el desarrollo del WB, pero la más conocida es la de Magnaval et al. ${ }^{(59)}$, quienes reportan el uso de cuatro bandas antigénicas específicas de 24 a $35 \mathrm{kDa}$, hallazgo que también ha sido confirmado en nuestro medio ${ }^{(60)}$.

Una limitación en la detección de anticuerpos lgG contra el parásito es que permanecen a un título casi constante durante un largo periodo en el paciente, aun después de haber finalizado el tratamiento antihelmíntico. Adiferencia de otras enfermedades infecciosas, los anticuerpos IgM han constituido un marcador clásico para identificar la etapa aguda de una enfermedad, sin embargo, estos no resultarían ser útiles ya que en la fase aguda, realizar el diagnóstico clínico de toxocarosis es raro y prácticamente nunca se sospecha de su presencia ${ }^{(6)}$. Como los síntomas clínicamente significativos aparecen en la fase crónica de la enfermedad, no sería de utilidad la detección de anticuerpos IgM, aunque existen pocos reportes del uso de este tipo de anticuerpo pero no se sabe si podría ser un marcador de la fase aguda o servir para diferenciar los casos recientes de toxocarosis sintomática ${ }^{(6,61,62)}$. Una estrategia que podría ayudar a identificar los casos activos o recientes de toxocarosis sería determinar la avidez de los anticuerpos IgG contra el parásito, ya que aquellos pacientes que tengan anticuerpos IgG con una pobre avidez, podrían ser catalogados como casos de infección reciente ${ }^{(6,63)}$.

Con el objetivo de seguir la evolución del tratamiento antihelmíntico del paciente, Magnaval et al. desarrollaron una prueba de ELISA para la detección de anticuerpos lgE 
anti-Toxocara en referencia a la elevada producción de IgE total que presentan muchos pacientes con toxocarosis sintomática ${ }^{(2,6,64,65)}$. Esta prueba resulta ser de utilidad en el $80 \%$ de los casos, ya que los niveles de lgE suelen decaer entre los cuatro y seis meses postratamiento ${ }^{(23,65)}$.

Debido a que las larvas de Toxocara no desarrollan a formas adultas en el ser humano y se encuentran restringidas a la forma larval migrando por ciertos órganos como el hígado y el pulmón, en algunos casos se puede detectar el ADN del parásito en estos órganos haciendo uso de la tecnología del PCR, sobre todo en el lavado bronquial que es más accesible; sin embargo, esta posiblidad todavía parece estar en sus comienzos ya que reportes preliminares, realizados en infecciones experimentales, han comunicado pobres resultados en términos de sensibilidad (66,67). Por otro lado, de mejorarse esta técnica molecular, se podría ayudar a establecer el verdadero agente etiológico de la causa de la enfermedad, que si bien es cierto se ha comentado mucho sobre $T$. canis, no hay que dejar de lado al $T$. cati, que también suele ser una causa de infecciones en humanos ${ }^{(68)}$, aunque se ha reportado infecciones producidas por larvas de otros nematodos de animales como el Ascaris suum y el Baylisascaris procyonis ${ }^{(69)}$

El uso de la biología molecular no resulta ser ajena al diagnóstico de la toxocarosis humana puesto que ya diversos autores han identificado, secuenciado y clonado los genes que codifican los diferentes antígenos de las larvas del $T$. canis ${ }^{(70,71)}$. En ese sentido, se han publicado numerosos trabajos acerca de la producción de antígenos recombinantes (rTES) para ser utilizados en nuevas pruebas diagnósticas en el futuro. De todos los rTES se conocen hasta el momento, el rTES-30, desarrollado por primera vez por Yamasaki y colaboradores en el año $2000{ }^{(72)}$ y un ELISA con una excelente sensibilidad y especificidad. En segundo lugar tenemos al rTES-120 (una glicoproteína de la pared de la larva, la que más produce el parásito, y que resulta ser un importante componente de los antígenos TES) que también fue propuesto para el desarrollo de un ELISA altamente especifico ${ }^{(73,74)}$. Actualmente, se ha reportado la combinación de tres rTES (rTES-26, rTES-30USM y el rTES120) asociado con la detección específica de anticuerpos de la subclase lgG4, que resultarían poseer mayor especificidad para el inmunodiagnóstico de la toxocarosis humana ${ }^{(75)}$.

\section{SEGUIMIENTO DE LA ENFERMEDAD Y EL TRATAMIENTO DEL PACIENTE}

Aquellos pacientes con síntomas respiratorios agudos de compromiso pulmonar (disnea, sibilancias) pueden necesitar ser hospitalizados para realizarles estudios con radiografía de tórax y así confirmar la presencia de lesiones. En cambio, aquellos con compromiso hepático, la hospitalización puede ser necesaria para procedimientos diagnósticos o terapéuticos como biopsia o cirugía láser ${ }^{(41)}$.

Para el control posterior del paciente es útil realizar el recuento de eosinófilos, estudios de imágenes de las lesiones y títulos de anticuerpos IgG e IgE mediante ELISA O WB, aunque estos no necesariamente disminuyen en un corto plazo, como ya se comentó anteriormente ${ }^{(2,23)}$. El estudio de muestras pareadas para evaluar los niveles de IgE total puede ayudar a realizar el seguimiento de la terapia antihelmíntica del paciente ${ }^{(2,5,6)}$. En casos pulmonares, deben obtenerse radiografías de tórax para verificar que los infiltrados hayan desaparecido. En los casos de compromiso hepático, el estudio de marcadores hepáticos (como las transaminasas o la fosfatasa alcalina) podrían ser necesarios para el control posterior. En caso de haber compromiso ocular, debe realizarse el estudio mediante la fondoscopía mensual o bimensual, según la remisión de la sintomatología (Tabla 1) ${ }^{(1,3,5)}$.

De lo anteriormente expuesto, se puede concluir que la toxocarosis humana es una importante zoonosis que, lamentablemente, todavía sigue siendo poco diagnosticada. Debería realizarse estudios en nuestro medio con el fin de conocer y considerar a esta zoonosis, puesto que posee un amplio espectro de características, tanto en la sintomatología clínica como en el diagnóstico de laboratorio.

\section{Conflictos de Interés}

Los autores declaran no tener conflictos de interés en la publicación de este artículo.

\section{REFERENCIAS BIBLIOGRÁFICAS}

1. Despommier D. Toxocariasis: clinical aspects, epidemiology, medical ecology, and molecular aspects. Clin Microbiol Rev. 2003;16(2):265-72.

2. Magnaval JF, Glickman LT, Dorchies P, Morassin B. Highlights of human toxocariasis. Korean $\mathrm{J}$ Parasitol. 2001;39(1):1-11.

3. Minvielle M, Niedfeld M, Ciarmela M, Basualdo J. Toxocariosis causada por Toxocara canis: aspectos clínico-epidemiológicos. Enf Infec Microbiol Clin. 1999;17(6):300-6.

4. Schantz PM, Glickman LT. Toxocaral visceral larva migrans. N Engl J Med. 1978;298(8):436-39.

5. Pawlowski Z. Toxocariasis in humans: clinical expression and treatment dilemma. J Helminthol. 2001;75(4):299-305.

6. Smith H, Holland C, Taylor M, Magnaval JF, Schantz P, Maizels R. How common is human toxocariasis? Towards standardizing our knowledge. Trends Parasitol. 2009;25(4):182-88. 
7. Taylor MR, Keane CT, O'Connor P, Mulvihill E, Holland C. The expanded spectrum of toxocaral disease. Lancet. 1988;1(8587):692-95.

8. Jacob CM, Pastorino AC, Peres BA, Mello EO, Okay Y, Oselka GW. Clinical and laboratorial features of visceral toxocariasis in infancy. Rev Inst Med Trop Sao Paulo. 1994;36(1):19-26.

9. Chan PW, Anuar AK, Fong MY, Debruyne JA, Ibrahim J. Toxocara seroprevalence and childhood asthma among Malaysian children. Pediatr Int. 2001;43(4):350-53.

10. Kustimur S, Dogruman Al F, Oguzulgen K, Bakir H, Maral I, Turktas $\mathbf{H}$, et al. Toxocara seroprevalence in adults with bronchial asthma. Trans R Soc Trop Med Hyg. 2007;101(3):270-74

11. López ML, Bojanich MV, Jacobacci JM, Sercic C, Michelini A, Alonso JM. Toxocara canis y asma bronquial. Medicina (B Aires). 2010;70(1):75-78.

12. Beaver PC, Snyder CH, Carrera GM, Dent JH, Lafferty JW. Chronic eosinophilia due to visceral larva migrans; report of three cases. Pediatrics. 1952;9(1):7-19.

13. Vijayan VK. Parasitic lung infections. Curr Opin Pulm Med. 2009;15(3):274-82

14. Friedman S, Hervada AR. Severe myocarditis with recovery in a child with visceral larva migrans. J Pediatr. 1960;56:91-96

15. Dao AH, Virmani R. Visceral larva migrans involving the myocardium: report of two cases and review of literature. Pediatr Pathol. 1986;6(4):449-56.

16. De Cock C, Lemaitre J, Deuvaert FE. Löeffler endomyocarditis: a clinical presentation as right ventricular tumor. J Heart Valve Dis. 1998;7(6):668-71.

17. Roig J, Romeu J, Riera C, Texido A, Domingo C, Morera J. Acute eosinophilic pneumonia due to toxocariasis with bronchoalveolar lavage findings. Chest. 1992;102(1):294-96.

18. Ashwath ML, Robinson DR, Katner HP. A presumptive case of toxocariasis associated with eosinophilic pleural effusion: case report and literature review. Am J Trop Med Hyg. 2004;71(6):764.

19. Kim MH, Jung JW, Kwon JW, Kim TW, Kim SH, Cho $\mathrm{SH}$, et al. A case of recurrent toxocariasis presenting with urticaria. Allergy Asthma Immunol Res. 2010;2(4):267-70.

20. Wilder HC. Nematode endophthalmitis. Trans Am Acad Ophthalmol Otolaryngol. 1950;55:99-109.

21. Rey A. Nematode endophthalmitis due to Toxocara. Br J Ophthalmol. 1962;46(10):616-18.

22. Dernouchamps JP, Verougstraete C, Demolder E. Ocular toxocariasis: a presumed case of peripheral granuloma. Int Ophthalmol. 1990;14(5-6):383-88.

23. Park SP, Park I, Park HY, Lee SU, Huh S, Magnaval JF. Five cases of ocular toxocariasis confirmed by serology. Korean J Parasitol. 2000;38(4):267-73.

24. Sabrosa NA, de Souza EC. Nematode infections of the eye: toxocariasis and diffuse unilateral subacute neuroretinitis. Curr Opin Ophthalmol. 2001;12(6):450-54

25. Finsterer J, Auer H. Neurotoxocarosis. Rev Inst Med Trop Sao Paulo. 2007:49(5):279-87.

26. Hotez PJ. Visceral and ocular larva migrans. Semin Neurol. 1993;13(2):175-79
27. Magnaval JF, Galindo V, Glickman LT, Clanet M. Human Toxocara infection of the central nervous system and neurological disorders: a case-control study. Parasitology. 1997;115(Pt 5):537-43

28. Hill IR, Denham DA, Scholtz CL. Toxocara canis larvae in the brain of a British child. Trans R Soc Trop Med Hyg. 1985;79(3):351-54

29. Skerrett $\mathbf{H}$, Holland CV. Variation in the larval recovery of Toxocara canis from the murine brain: implications for behavioural studies. J Helminthol. 1997;71(3):253-55

30. Piergili Fioretti D, Moretti A, Mughetti L, Bruschi F. Eosinophilia, granuloma formation, migratory behaviour of second stage larvae in murine Toxocara canis infection. Effect of the inoculum size. Parassitologia. 1989;31(23):153-66

31. Cox DM, Holland CV. The relationship between numbers of larvae recovered from the brain of Toxocara canisinfected mice and social behaviour and anxiety in the host. Parasitology. 1998;116(Pt 6):579-94.

32. Dunsmore JD, Thompson RC, Bates IA. The accumulation of Toxocara canis larvae in the brains of mice. Int J Parasitol. 1983;13(5):517-21.

33. Moreira-Silva SF, Rodrigues MG, Pimenta JL, Gomes CP, Freire LH, Pereira FE. Toxocariasis of the central nervous system: with report of two cases. Rev Soc Bras Med Trop. 2004;37(2):169-74.

34. Taylor MR, Keane CT, O'Connor P, Girdwood RW, Smith H. Clinical features of covert toxocariasis. Scand J Infect Dis. 1987;19(6):693-96.

35. Feldman GJ, Parker HW. Visceral larva migrans associated with the hypereosinophilic syndrome and the onset of severe asthma. Ann Intern Med. 1992; 116: 838840.

36. Buijs J, van Knapen F. Toxocara infection in children and the relation with allergic manifestations. Vet $Q$. 1994;16(Suppl 1):13S-14S

37. Inoue K, Inoue Y, Arai T, Nawa Y, Kashiwa Y, Yamamoto $\mathbf{S}$, et al. Chronic eosinophilic pneumonia due to visceral larva migrans. Intern Med. 2002;41(6):478-82.

38. Wolfrom E, Chêne G, Boisseau H, Beylot C, Géniaux M, Taïeb A. Chronic urticaria and Toxocara canis. Lancet. 1995;345(8943):196.

39. Walsh SS, Robson WJ, Hart CA. Acute transient myositis due to Toxocara. Arch Dis Child. 1988;63(9):1087-88.

40. Kraus A, Valencia X, Cabral AR, de la Vega G. Visceral larva migrans mimicking rheumatic diseases. J Rheumatol. 1995;22(3):497-500.

41. Huapaya $P$, Espinoza $Y$, Roldán $W$, Jiménez $S$. Toxocariosis humana: ¿problema de salud pública? An Fac Med (Lima). 2009;70(4):283-90.

42. Espinoza YA, Huapaya PH, Roldán WH, Jiménez S, Arce Z, Lopez E. Clinical and serological evidence of Toxocara infection in school children from Morrope district, Lambayeque, Peru. Rev Inst Med Trop Sao Paulo. 2008;50(2):101-5

43. Roldán WH, Espinoza YA, Atúncar A, Ortega E, Martinez A, Saravia M. Frequency of eosinophilia and risk factors and their association with Toxocara infection in schoolchildren during a health survey in the north of Lima, Peru. Rev Inst Med Trop Sao Paulo. 2008;50(5):273-78. 
44. Gawor J, Borecka A, Zarnowska H, Marczyńska M, Dobosz S. Environmental and personal risk factors for toxocariasis in children with diagnosed disease in urban and rural areas of central Poland. Vet Parasitol. 2008; 155(3-4):217-22.

45. Sugane K, Oshima T. Purification and characterization of excretory and secretory antigen of Toxocara canis larvae. Immunology. 1983;50(1):113-20.

46. Sugane K, Oshima T. Induction of peripheral blood eosinophilia in mice by excretory and secretory antigen of Toxocara canis larvae. J Helminthol. 1984;58(2):143-147.

47. Sugane K, Oshima T. Interrelationship of eosinophilia and IgE antibody production to larval ES antigen in Toxocara canis infected mice. Parasite Immunol. 1984;6(5):409-20.

48. Savigny DH. In vitro maintenance of Toxocara canis larvae and a simple method for the production of Toxocara ES antigen for use in serodiagnostic tests for visceral larva migrans. J Parasitol. 1975;61(4):781-82.

49. De Savigny DH, Voller A, Woodruff AW. Toxocariasis: serological diagnosis by enzyme immunoassay. J Clin Pathol. 1979;32(3):284-88

50. Felberg NT, Shields JA, Federman JL. Antibody to Toxocara canis in the aqueous humor. Arch Ophthalmol. 1981;99(9):1563-64

51. de Visser L, Rothova A, de Boer JH, van Loon AM, Kerkhoff FT, Canninga-van Dijk MR, et al. Diagnosis of ocular toxocariasis by establishing intraocular antibody production. Am J Ophthalmol. 2008;145(2):369-74.

52. Vidal JE, Sztajnbok J, Seguro AC. Eosinophilic meningoencephalitis due to Toxocara canis: case report and review of the literature. Am J Trop Med Hyg. 2003;69(3):341-43.

53. Goffette S, Jeanjean AP, Duprez TP, Bigaignon G, Sindic CJ. Eosinophilic pleocytosis and myelitis related to Toxocara canis infection. Eur J Neurol. 2000;7(6):703-6.

54. Eberhardt O, Bialek R, Nägele T, Dichgans J. Eosinophilic meningomyelitis in toxocariasis: case report and review of the literature. Clin Neurol Neurosurg. 2005;107(5):432-38.

55. Cypess RH, Karol MH, Zidian JL, Glickman LT, Gitlin D. Larva-specific antibodies in patients with visceral larva migrans. J Infect Dis. 1977;135(4):633-40.

56. Roldán W, Cornejo W, Espinoza Y. Evaluation of the dot enzyme-linked immunosorbent assay in comparison with standard ELISA for the immunodiagnosis of human toxocariasis. Mem Inst Oswaldo Cruz. 2006;101(1):71-74.

57. Elefant GR, Shimizu SH, Sanchez MC, Jacob CM, Ferreira AW. A serological follow-up of toxocariasis patients after chemotherapy based on the detection of $\lg G$, $\lg A$, and IgE antibodies by enzyme-linked immunosorbent assay. J Clin Lab Anal. 2006;20(4):164-72.

58. Roldán WH, Espinoza YA, Huapaya PE, Huiza AF, Sevilla $\mathbf{C R}$, Jiménez $\mathbf{S}$. Frequency of human toxocariasis in a rural population from Cajamarca, Peru determined by DOT-ELISA test. Rev Inst Med Trop Sao Paulo. 2009;51(2):67-71.

59. Magnaval JF, Fabre $R$, Maurières $P$, Charlet JP, de Larrard B. Application of the western blotting procedure for the immunodiagnosis of human toxocariasis. Parasitol Res. 1991;77(8):697-702.

60. Roldán WH, Espinoza YA. Evaluation of an enzymelinked immunoelectrotransfer blot test for the confirmatory serodiagnosis of human toxocariasis. Mem Inst Oswaldo Cruz. 2009;104(3):411-18.
61. Arango CA. Visceral larva migrans and the hypereosinophilia syndrome. South Med J. 1998;91(9):882-83.

62. Kaplan M, Kalkan A, Hosoglu S, Kuk S, Ozden M, Demirdag $\mathbf{K}$, et al. The frequency of Toxocara infection in mental retarded children. Mem Inst Oswaldo Cruz. 2004;99(2):121-25.

63. Dziemian E, Zarnowska H, Kołodziej-Sobocińska M, Machnicka B. Determination of the relative avidity of the specific IgG antibodies in human toxocariasis. Parasite Immunol. 2008;30(3):187-90.

64. Magnaval JF, Fabre R, Maurières $P$, Charlet JP, de Larrard B. Evaluation of an immunoenzymatic assay detecting specific anti-Toxocara immunoglobulin $E$ for diagnosis and posttreatment follow-up of human toxocariasis. J Clin Microbiol. 1992;30(9):2269-74.

65. Magnaval JF, Faufingue JH, Morassin B, Fabre R. Eosinophil cationic protein, specific IgE and IgG4 in human toxocariasis. J Helminthol. 2006;80(4):417-23.

66. Li MW, Lin RQ, Chen $H H$, Sani RA, Song $H Q$, Zhu XQ. PCR tools for the verification of the specific identity of ascaridoid nematodes from dogs and cats. Mol Cell Probes. 2007;21(5-6):349-54.

67. Fogt-Wyrwas R, Jarosz W, Mizgajska-Wiktor H. Utilizing a polymerase chain reaction method for the detection of Toxocara canis and $T$. cati eggs in soil. J Helminthol. 2007;81(1):75-78.

68. Fisher M. Toxocara cati: an underestimated zoonotic agent. Trends Parasitol. 2003;19(4):167-70.

69. Lee AC, Schantz PM, Kazacos KR, Montgomery SP, Bowman DD. Epidemiologic and zoonotic aspects of ascarid infections in dogs and cats. Trends Parasitol. 2010;26(4):155-61.

70. Tetteh KK, Loukas A, Tripp C, Maizels RM. Identification of abundantly expressed novel and conserved genes from the infective larval stage of Toxocara canis by an expressed sequence tag strategy. Infect Immun. 1999;67(9):4771-79.

71. Maizels RM, Tetteh KK, Loukas A. Toxocara canis: genes expressed by the arrested infective larval stage of a parasitic nematode. Int J Parasitol. 2000;30(4):495-508.

72. Yamasaki H, Araki K, Lim PK, Zasmy N, Mak JW, Taib $\mathbf{R}$, et al. Development of a highly specific recombinant Toxocara canis second-stage larva excretory-secretory antigen for immunodiagnosis of human toxocariasis. J Clin Microbiol. 2000;38(4):1409-13.

73. Fong MY, Lau YL, Init I, Jamaiah I, Anuar AK, Rahmah N. Recombinant expression of Toxocara canis excretorysecretory antigen TES-120 in Escherichia coli. Southeast Asian J Trop Med Public Health. 2003;34(4):723-26.

74. Fong MY, Lau YL. Recombinant expression of the larval excretory-secretory antigen TES-120 of Toxocara canis in the methylotrophic yeast Pichia pastoris. Parasitol Res. 2004;92(2):173-76.

75. Mohamad S, Azmi NC, Noordin R. Development and evaluation of a sensitive and specific assay for diagnosis of human toxocariasis by use of three recombinant antigens (TES-26, TES30USM, and TES-120). J Clin Microbiol. 2009;47(6):1712-17.

Correspondencia: William H. Roldán

Dirección: Calle José Santos Chocano 199, Callao 02, Perú.

Teléfono: (511) 452-1742 / (511) 619-7000 anexo 4409

Correo electrónico: willyroldan23@hotmail.com 